Check for updates

Cite this: RSC Adv., 2017, 7, 40354

Received 19th June 2017

Accepted 14th August 2017

DOI: $10.1039 / \mathrm{c} 7 \mathrm{ra06841g}$

rsc.li/rsc-advances

\section{Low temperature catalytic hydrolysis of carbon disulfide over nano-active carbon based catalysts prepared by liquid phase deposition}

\author{
Kai Li, ${ }^{a}$ Xin Song, ${ }^{a}$ Guijian Zhang, ${ }^{a}$ Chi Wang, ${ }^{b}$ Ping Ning, (D) *a Xin Sun ${ }^{a}$ \\ and Lihong Tang ${ }^{a}$
}

In this work, a series of nano-carbon based catalysts loaded with metal oxides were prepared via liquid phase deposition, and used for low temperature catalytic hydrolysis of carbon disulfide $\left(\mathrm{CS}_{2}\right)$. The influences of preparation conditions for catalytic activity were investigated. These factors included species and content of metal oxides, ratio of $\mathrm{F}$ : Fe, solution $\mathrm{pH}$, and calcination temperature. The results showed that catalysts with $0.2 \mathrm{~mol} \mathrm{~L}{ }^{-1} \mathrm{Fe}$ ion after calcining at $500^{\circ} \mathrm{C}$ had good catalytic activity for the catalytic hydrolysis of $\mathrm{CS}_{2}$. Furthermore, the catalytic hydrolysis activity could reach the best performance with the optimum preparation conditions with an $\mathrm{F}$ : Fe ratio of $3: 1$, and a solution $\mathrm{pH}$ of 5.1. The metal species affected the catalytic hydrolysis of $\mathrm{CS}_{2}$ and the oxidation of $\mathrm{H}_{2} \mathrm{~S}$. The solution $\mathrm{pH}$ and fluoride affected the generation of $\mathrm{Fe}^{3+}\left(\mathrm{Fe}_{2} \mathrm{O}_{3}\right)$. The chemical composition, structure and surface properties were characterized by $\mathrm{X}$-ray diffractometry (XRD), temperature programmed desorption of carbon monoxide (CO-TPD), X-ray photoelectron spectrum (XPS) and Brunauer-Emmett-Teller measurements $(B E T)$. The $X R D$ and $B E T$ results showed that the calcination temperature controlled the crystalline phase and generation of $\mathrm{Fe}_{2} \mathrm{O}_{3}$ and affected the properties of specific surface area and pore structure.

\section{Introduction}

Carbon disulfide $\left(\mathrm{CS}_{2}\right)$, as a major component of organic sulfur compounds, derives mainly from industrial tail gases, such as in the coal, natural gas, petroleum, crude oil, and streams industries. $^{1,2}$ It has a negative effect in many catalysis and synthesis processes (even as low as $1 \mathrm{ppm}$ concentration). ${ }^{3} \mathrm{CS}_{2}$ can not only pollute the environment but also poison the catalysts. ${ }^{3,4}$ Therefore, the removal of $\mathrm{CS}_{2}$ is necessary. Many methods have been developed to remove $\mathrm{CS}_{2}$ from Claus tail gas and other processed gas streams. The main methods for $\mathrm{CS}_{2}$ removal includes reduction, adsorption, photolysis, oxidation, catalytic hydrolysis, etc. ${ }^{5-11}$ Among these methods, catalytic hydrolysis was recognized as the most suitable removal process due to the characteristics of mild reaction conditions, low cost, and higher conversion efficiency. ${ }^{\mathbf{1 2}}$ Recently, many studies focused on high temperature catalytic hydrolysis over $200{ }^{\circ} \mathrm{C}$, but few researches focused on low temperature catalytic hydrolysis below $100{ }^{\circ} \mathrm{C}$. Therefore, it is valuable to study $\mathrm{CS}_{2}$ removal at low temperature $\left(<100{ }^{\circ} \mathrm{C}\right)$ due to that it will be more

${ }^{a}$ Faculty of Environmental Science and Engineering, Kunming University of Science and Technology, Kunming; 650500, China. E-mail: ningpingkmust@163.com; Fax: +86871-65920507; Tel: +86-871-65920507

${ }^{b}$ Faculty of Chemical Engineering, Kunming University of Science and Technology, Kunming, 650500, China economical. ${ }^{\mathbf{1 3}}$ In the recent years, researchers have prepared kinds of new catalysts to increase the efficiency of $\mathrm{CS}_{2}$ catalytic hydrolysis at low temperature, such as $\gamma-\mathrm{Al}_{2} \mathrm{O}_{3}, \mathrm{TiO}_{2}$, hydrotalcite-like compounds, carbon based catalyst. ${ }^{\mathbf{1 4 - 1 7}}$ Activated carbon has the special characteristics of stable structure, well-developed porous structure, large surface area and porous structure and potential bio-compatibility, and it has got a lot of attention. ${ }^{4}$ Many people have modified the surface properties of activated carbons to improve its function, which made it meet the growing needs of removal $\mathrm{CS}_{2}$ at low temperature. ${ }^{\mathbf{1 4 , 1 8 , 1 9}}$

With the development of nanotechnology, further studies have been carried out on nanoparticles, which defined a kind of ordered assembly structure that a nanoparticle is covered with another through a bond or other forces. ${ }^{\mathbf{2 0}}$ Recently, nanoparticles have attracted considerable interest because of the fact that their characteristics, such as magnetic, optical, electrical and catalysis. These characteristics can be easily controlled by changing their structure, compositions and particle size by appropriate method. Many reports also have showed that nanoparticles covered by the shell (such as noble metal, metal oxides and magnetic ferrites) had improved the performance in removing environmental pollutants. ${ }^{21-23}$ Many methods have been developed to prepare nanoparticles include the sol-gel method, hydrothermal treatment method, self-assembly method and liquid phase deposition method (LPD), etc. ${ }^{24-27}$ Among these methods, LPD was treated as the most promising 
process due to mild reaction condition, cost-effective and adjustability of nanoparticle properties. ${ }^{28}$

In the recent studies, there were a large number of researches about the nanoparticles catalysts for aqueous environmental pollutants. ${ }^{21-23}$ However, few researches focused on removing gas pollutants in the atmospheric, especially catalytic hydrolysis of $\mathrm{CS}_{2}$ at low temperature $\left(<100{ }^{\circ} \mathrm{C}\right)$. In this study, nano-carbon based catalysts were used for $\mathrm{CS}_{2}$ removal at lowtemperature $\left(50{ }^{\circ} \mathrm{C}\right)$. The influences of the preparation conditions included species and content of metal oxides, molar ratio of $\mathrm{F}$ : metal ions, solution $\mathrm{pH}$ and calcination temperature were investigated. Meanwhile, the chemical composition, structure and surface properties were characterized by X-ray diffractometry (XRD), X-ray photoelectron spectrum (XPS), temperature programmed desorption of carbon-monoxide (CO-TPD) and Brunauer-Emmett-Teller measurements (BET).

\section{Materials and methods}

\subsection{Catalysts preparation}

All reagents were at analytical grade. The nano-carbon (the average particle size is $40 \mathrm{~nm}$ ) came from the Beijing DK nano technology Co. LTD. The nanoparticles catalysts were synthesized with liquid phase deposition method. ${ }^{29}$ Fluoride was used to prepare the precursor of $\mathrm{Fe}^{3+}\left(\mathrm{Fe}_{2} \mathrm{O}_{3}\right) .40 \mathrm{wt} \%$ hydrofluoric acid solution (HF) was introduced into a $50 \mathrm{~mL}$ metal salt $\left(\mathrm{NiCl}_{2} \cdot 6 \mathrm{H}_{2} \mathrm{O}, \mathrm{Cu}\left(\mathrm{CH}_{3} \mathrm{COO}\right)_{2}, \mathrm{Zn}\left(\mathrm{CH}_{3} \mathrm{COO}\right)_{2} \cdot 2 \mathrm{H}_{2} \mathrm{O}, \mathrm{FeCl}_{2} \cdot 4 \mathrm{H}_{2} \mathrm{O}\right.$ and $\left.\mathrm{Mn}\left(\mathrm{CH}_{3} \mathrm{COO}\right)_{2} \cdot 4 \mathrm{H}_{2} \mathrm{O}\right)$ solution, and the concentration of metal salt was kept at specific $\left(0.05-0.4 \mathrm{~mol} \mathrm{~L}^{-1}\right)$. When the influence of metal species and content were investigated, the content of $\mathrm{F}$ was fixed. When the influence of $\mathrm{F}$ was investigated, the content of Fe was fixed. The addition amount of hydrofluoric acid solution was according to the expected molar ratio of $\mathrm{F}$ to metal atoms in the mixed solution. In this study, the range of molar ratio of $\mathrm{F}$ to metal atoms was from $1: 1$ to $5: 1$. The solution $\mathrm{pH}$ was adjusted to $4.7-5.3$ by adding dropwise $25 \mathrm{wt} \%$ ammonia hydroxide solution. Then, $50 \mathrm{~mL}$ nano-carbon suspension (the mass fraction of nanocarbon was $1 \%$ in the suspension) was added into above mixed solution. Next, these samples were treated with bathing at $60^{\circ} \mathrm{C}$ and stirring for $2 \mathrm{~h}$, and then were separated by centrifugal. In this process, $\mathrm{Fe}^{2+}$ was converted into $\mathrm{Fe}^{3+}$. Then, they were washed twice with distilled water, and dried at $60{ }^{\circ} \mathrm{C}$ in the drying oven for $12 \mathrm{~h}$. Finally, these samples were calcined for $2 \mathrm{~h}$ at specific temperatures $\left(300{ }^{\circ} \mathrm{C}, 400{ }^{\circ} \mathrm{C}, 500{ }^{\circ} \mathrm{C}, 600{ }^{\circ} \mathrm{C}, 700{ }^{\circ} \mathrm{C}\right)$ in a pipe furnace in nitrogen atmosphere with $82.4 \mathrm{kPa}$ of atmospheric pressure.

\subsection{Desulfurization test}

At the first, the nanoparticles prepared in above process was crushed and sieved to 40-60 mesh size for this study. Desulfurization tests were carried out under atmospheric pressure in a fixed-bed quartz reactor system $(3 \mathrm{~mm}$ inside diameter $\times 100$ $\mathrm{mm}$ length). Fig. 1 shows a schematic diagram of the apparatus for the catalytic activity measurements.

To ensure that the catalyst could not escape from the vessel during the operation, the catalyst was loaded into the fixed bed

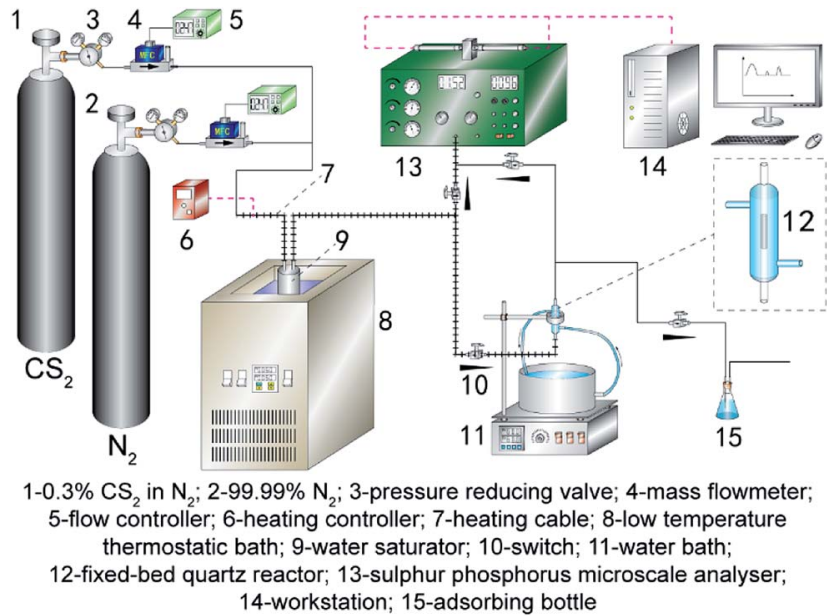

Fig. 1 The schematic diagram of the apparatus for the catalytic activity measurements.

and a wad of cotton wool was inserted into the reactor. $\mathrm{CS}_{2}$ from a gas cylinder $\left(0.3 \% \mathrm{CS}_{2}\right.$ in $\left.\mathrm{N}_{2}\right)$ was diluted with nitrogen (99.99\%) to the required concentration $\left(\mathrm{CS}_{2}: 80-90 \mathrm{ppm}\right)$. The overall flow rate was controlled using calibrated mass flow controllers, and the overall gas hourly space velocity (GHSV) of the reaction mixture was standardized at $10000 \mathrm{~h}^{-1}$. Water was introduced using a saturator system. The temperature of this reactor was controlled by a water-bath with a circulating pump to an accuracy of $\pm 0.1^{\circ} \mathrm{C}$. The relative humidity (RH) of mixture gas was $11.8 \%$. The concentrations of $\mathrm{CS}_{2}$ in the feed and effluent of reactor were collected by a HC-6 sulfur phosphorus microscale analyzer. The conversion of $\mathrm{CS}_{2}$ is determined by analyzing the inlet and outlet concentrations of $\mathrm{CS}_{2}$ :

$$
\mathrm{CS}_{2} \text { conversion }(\%)=\frac{\mathrm{CS}_{2_{\text {inlet }}}-\mathrm{CS}_{2_{\text {outlet }}}}{\mathrm{CS}_{2_{\text {inlet }}}} \times 100
$$

In addition, all the experimental operating conditions are the same so that no other external factor to affect the susceptibility of catalysts. Therefore, a longer reaction time (keeping above $90 \%$ of $\mathrm{CS}_{2}$ conversion) represents a higher catalytic hydrolysis activity.

\subsection{Characterization}

X-ray diffraction (XRD, D/MAX-2200 from Rigaku company) patterns were recorded with a diffractometer operated at $36 \mathrm{kV}$ and $30 \mathrm{~mA}$ by using Ni filtered $\mathrm{Cu} \mathrm{K} \alpha$ radiation $(\lambda=0.15406 \mathrm{~nm})$ at a rate of $5^{\circ} \mathrm{min}^{-1}$ from $2 \theta=10^{\circ}$ to $80^{\circ}$. X-ray photoelectron spectrum (XPS, AXIS-ultra from Kratos) analysis used Al K $\alpha$ radiation with energy of the $\mathrm{Al}$ target and a power of $200 \mathrm{~W}$. The metal oxides dispersion on catalyst surface was measured by a temperature programmed desorption of carbon monoxide (CO-TPD, Belcat II from Belcat) with a thermal conductivity detector (TCD) setup using $100 \mathrm{mg}$ of catalyst. Nitrogen adsorption-desorption measurements were carried out using a Quantachrome NOVA2000e surface area analyzer. Specific surface areas, mesoporous and micropore parameter data 
calculated by Brunauer-Emmett-Teller (BET), Barrett-JoynerHalenda (BJH) and Horvath-Kawazoe (HK) methods.

\section{Results and discussion}

\subsection{Influence of metal oxide species on catalytic hydrolysis of $\mathrm{CS}_{2}$}

The catalytic hydrolysis of $\mathrm{CS}_{2}$ over a series of nano-catalysts with different metal oxides additives were investigated at $50{ }^{\circ} \mathrm{C}$. In this section, the content of metal ion were all $0.1 \mathrm{~mol} \mathrm{~L}^{-1}$; $\mathrm{F}$ : Fe was $3: 1$; $\mathrm{pH}$ was 5.1 ; calcination temperature was $500{ }^{\circ} \mathrm{C}$. From Fig. 2, it can be seen that there was a significant difference of activity among these catalysts. The $\mathrm{CS}_{2}$ conversions of a series nano-catalysts were lower than that of blank nano-AC, excepted for Fe/nano-AC. Meanwhile, the following order of activity was obtained: $\mathrm{Fe} /$ nano-AC $>$ nano-AC $>\mathrm{Zn} /$ nano-AC $>\mathrm{Cu} /$ nano-AC $>\mathrm{Mn} /$ nano-AC $>\mathrm{Ni} /$ nano-AC. So only the $\mathrm{Fe} /$ nano-AC catalyst could effectively enhance the $\mathrm{CS}_{2}$ conversion. From the results of activity test, for Fe/nano-AC, above $90 \% \mathrm{CS}_{2}$ conversion was observed for about $330 \mathrm{~min}$. However, for blank nano-AC, above $90 \% \mathrm{CS}_{2}$ conversion only last $240 \mathrm{~min}$. It indicated that the removal process of $\mathrm{CS}_{2}$ might be adsorption reaction on the surface of nano-AC, and might be catalytic hydrolysis reaction on the surface of $\mathrm{Fe}_{2} \mathrm{O}_{3}$.

The reason may be that $\mathrm{Fe}$ (as a transition metal) can promote the catalytic hydrolysis activity of $\mathrm{CS}_{2}$. From previous studies, it's apparent that the Fe-S binding energy of intermediate strength $(-4.5 \mathrm{eV})$ provided the optimum catalyst performance. ${ }^{30}$ Besides, the outer shell of the Fe ion is a kind of unfilled structure, which provides more effective nuclear charge. Therefore, the kind of texture is conducive to generate coordination compounds in the process of reaction. As an intermediate product, the coordination compounds can provide coordination catalysis effect and related surface reaction to promote the catalysis reaction. In previous study, $\mathrm{Fe}$ also showed high catalytic hydrolysis activity for $\mathrm{CS}_{2}$ and low

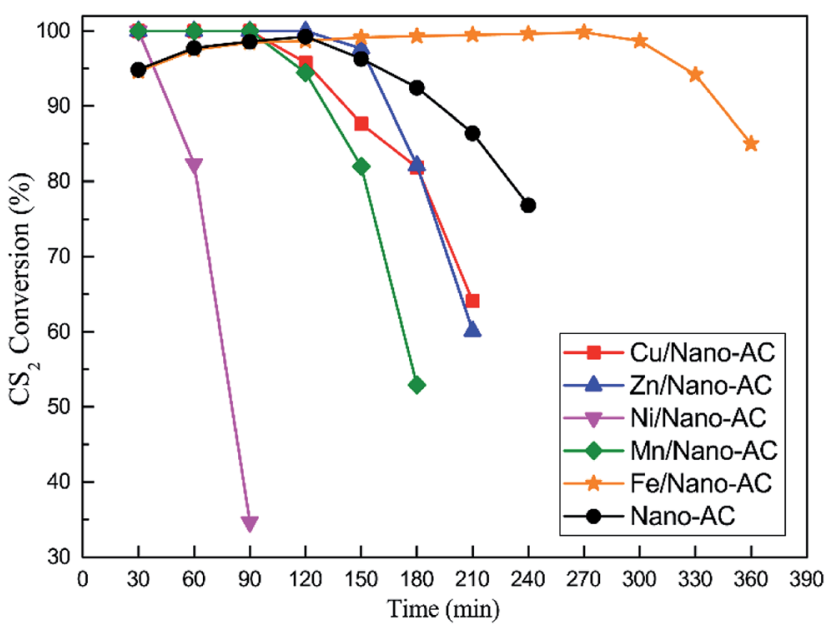

Fig. 2 Catalytic hydrolysis of $\mathrm{CS}_{2}$ over nano-AC modified by different metal oxides (reaction conditions: 90 ppm CS C $_{2}$ GHSV $=10000 \mathrm{~h}^{-1}$; reaction temperature $=50{ }^{\circ} \mathrm{C} ; \mathrm{RH}=11.8 \%$ ). oxidation activity for $\mathrm{H}_{2} \mathrm{~S} .{ }^{4}$ Due to high catalytic hydrolysis activity, Fe could improve the hydrolysis efficiency. Furthermore, low oxidation activity decreased the generation of sulfate (the oxidation product of $\mathrm{H}_{2} \mathrm{~S}$ ), which could prolong the lifetime of catalyst. Therefore, Fe was the optimal metal.

\subsection{Influence of Fe content on catalytic hydrolysis of $\mathrm{CS}_{2}$}

In order to investigate the influence of different Fe contents in the preparation process of $\mathrm{Fe} /$ nano-AC for catalytic hydrolysis activity of $\mathrm{CS}_{2}, 0.05 \mathrm{~mol} \mathrm{~L}^{-1}, 0.1 \mathrm{~mol} \mathrm{~L} \mathrm{~L}^{-1}, 0.2 \mathrm{~mol} \mathrm{~L}^{-1}$, $0.3 \mathrm{~mol} \mathrm{~L}^{-1}$ and $0.4 \mathrm{~mol} \mathrm{~L}^{-1} \mathrm{Fe}$ content were investigated. In this section, other preparation conditions were as follows: $\mathrm{F}$ : Fe was $3: 1$; pH was 5.1 ; calcination temperature was $500{ }^{\circ} \mathrm{C}$. As shown in Fig. 3, the $\mathrm{CS}_{2}$ removal efficiency over Fe/nano-AC catalysts initially increased and then decreased with increasing Fe content. Fe/nano-AC showed best catalytic activity when the Fe content was $0.2 \mathrm{~mol} \mathrm{~L}^{-1}$, and above $90 \% \mathrm{CS}_{2}$ conversion last $540 \mathrm{~min}$ at least. Contrarily, $\mathrm{Fe}(0.05) /$ nano-AC showed lowest catalytic activity, and above $90 \% \mathrm{CS}_{2}$ conversion only last $210 \mathrm{~min}$. Furthermore, the catalysts coated by different Fe contents could increase the catalytic activity compared to blank nano-AC.

Generally, the process of the crystal growth is divided into two types: homogeneous nucleation and heterogeneous nucleation. In comparison to the homogeneous nucleation, the new phase formed and developed on the original solid phase surface in the processes of crystal nucleation and growth of heterogeneous system. Meanwhile, the increase of the surface free energy in heterogeneous system is less than that of homogeneous. As a result, the molecules nucleation and growth in the interface of heterogeneous is better than that of homogeneous system. Therefore, in order to decrease homogeneous nucleation as much as possible and deposit a large amount of reactants on nano-AC surface, the saturation degree of solution should be controlled reasonable range when the Fe/nano-AC was prepared by LPD. Meanwhile, many studies showed that



Fig. 3 Catalytic hydrolysis of $\mathrm{CS}_{2}$ over $\mathrm{Fe} /$ nano-AC modified by different Fe content (reaction conditions: 90 ppm CS 2 ; GHSV = $10000 \mathrm{~h}^{-1}$; reaction temperature $=50{ }^{\circ} \mathrm{C} ; \mathrm{RH}=11.8 \%$ ). 
the supersaturation degree of solution was directly affected by metal ion content and $\mathrm{pH}$, etc. ${ }^{\mathbf{2 4}}$

Therefore, the Fe could deposit largely on the surface of nano-carbon when the Fe content was close to $0.2 \mathrm{~mol} \mathrm{~L}^{-1}$, and the catalyst had highest efficiency on catalytic hydrolysis of $\mathrm{CS}_{2}$. When the $\mathrm{Fe}$ content was above $0.3 \mathrm{~mol} \mathrm{~L}^{-1}$, the selfcondensation of iron complex compound is formed with increasing of Fe content. Table 1 showed the metal dispersion on the surface of Fe/nano-AC modified by different Fe content. From Table 1, the metal dispersion increased from $1.99 \%$ to 8.01\% when Fe content was low $\left(0.05-0.2 \mathrm{~mol} \mathrm{~L}^{-1}\right)$, but the metal dispersion decreased from $8.01 \%$ to $5.45 \%$ when $\mathrm{Fe}$ contents was high $\left(>0.2 \mathrm{~mol} \mathrm{~L}^{-1}\right)$. Furthermore, the micropores or mesoporous on the surface of nano-carbon may be blocked by the excessive $\mathrm{Fe}_{2} \mathrm{O}_{3}$. The surface adsorption sites or active of catalysts would be excessively overlapped, which leads to the catalytic efficiency decrease. From Table 2, it can be concluded that Fe content (0.05-0.3 $\mathrm{mol} \mathrm{L}^{-1}$ ) affected the surface area and pore volume. Furthermore, there was no obvious influence for the surface area and pore volume when Fe content was above $0.3 \mathrm{~mol} \mathrm{~L}^{-1}$. When the Fe content was below $0.2 \mathrm{~mol} \mathrm{~L}^{-1}$, there was not enough Fe deposited on the nano-AC surface. As the main active component, low Fe dispersion led to low catalytic hydrolysis activity.

\subsection{Influence of molar ratio of $\mathrm{F}: \mathrm{Fe}$ on catalytic hydrolysis of $\mathrm{CS}_{2}$}

When the Fe content was confirmed, the molar ratio of $\mathrm{F}: \mathrm{Fe}$ was determined with the content of $\mathrm{F}$. It means that higher ratio of $\mathrm{F}$ : Fe represents a higher content of $\mathrm{F}$. The relationship between the catalytic hydrolysis activity of $\mathrm{CS}_{2}$ and the ratio of $\mathrm{F}$ : Fe was investigated, and the desulfurization tests showed in Fig. 4. In this section, the content of Fe was $0.2 \mathrm{~mol} \mathrm{~L}^{-1}$; $\mathrm{pH}$ was 5.1 ; calcination temperature was $500{ }^{\circ} \mathrm{C}$. The $\mathrm{CS}_{2}$ removal efficiency initially increased and then decreased with increasing

Table 1 Metal dispersion of Fe/nano-AC modified by different Fe content

\begin{tabular}{lll}
\hline Samples & Dispersion $(\%)$ & Fe content $\left(\mathrm{Fe}_{2} \mathrm{O}_{3}, \mathrm{wt} \%\right)$ \\
\hline $\mathrm{Fe}(0.05) /$ nano-AC & 1.99 & 15.5 \\
$\mathrm{Fe}(0.2) /$ nano-AC & 8.01 & 25.7 \\
$\mathrm{Fe}(0.4) /$ nano-AC & 5.45 & 29.3
\end{tabular}

Table 2 Porosity parameters of Fe/nano-AC modified by different Fe content

\begin{tabular}{llll}
\hline Samples & $\begin{array}{l}\text { Surface area } \\
\left(\mathrm{m}^{2} \mathrm{~g}^{-1}\right)\end{array}$ & $\begin{array}{l}\text { Total pore volume } \\
\left(\mathrm{cm}^{3} \mathrm{~g}^{-1}\right)\end{array}$ & $\begin{array}{l}\text { Average pore } \\
\text { diameter }(\mathrm{nm})\end{array}$ \\
\hline $\mathrm{Fe}(0.05) /$ nano-AC & 395 & 0.32 & 3.28 \\
$\mathrm{Fe}(0.2) /$ nano-AC & 381 & 0.32 & 3.26 \\
$\mathrm{Fe}(0.3) /$ nano-AC & 354 & 0.29 & 3.27 \\
$\mathrm{Fe}(0.4) /$ nano-AC & 357 & 0.29 & 3.33
\end{tabular}

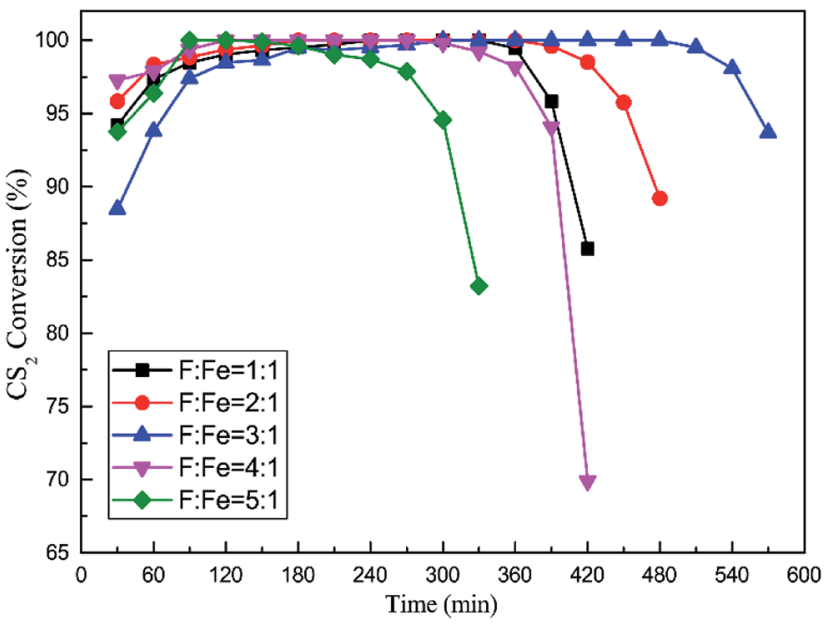

Fig. 4 Catalytic hydrolysis of $\mathrm{CS}_{2}$ over Fe/nano-AC modified by different $\mathrm{F}$ : Fe ratio (reaction conditions: $90 \mathrm{ppm} \mathrm{CS}_{2}$; $\mathrm{GHSV}=$ $10000 \mathrm{~h}^{-1}$; reaction temperature $=50{ }^{\circ} \mathrm{C} ; \mathrm{RH}=11.8 \%$ ).

molar ratio of $\mathrm{F}$ : Fe. Compared to blank nano-AC, the catalysts prepared by different ratio of $\mathrm{F}:$ Fe could enhance the catalytic hydrolysis activity of $\mathrm{CS}_{2}$. Fe/nano-AC showed best catalytic activity when the $\mathrm{F}$ : Fe was $3: 1$, and above $90 \% \mathrm{CS}_{2}$ conversion last $540 \mathrm{~min}$ at least. Contrarily, $\mathrm{Fe} /$ nano-AC showed lowest catalytic activity when $\mathrm{F}: \mathrm{Fe}$ was $5: 1$.

The previous research ${ }^{29}$ showed that the $\mathrm{F}$ content was a main influence factor for the formation of $\mathrm{Fe}^{3+}\left(\mathrm{Fe}_{2} \mathrm{O}_{3}\right)$ when the Fe content was fixed. Therefore, when $\mathrm{F}: \mathrm{Fe}$ was higher than $3: 1$, the amount of $\mathrm{F}$ inevitably increased, which reduced the amount of $\mathrm{Fe}^{3+}\left(\mathrm{Fe}_{2} \mathrm{O}_{3}\right)$. As a result, the catalytic hydrolysis efficiency of $\mathrm{CS}_{2}$ over $\mathrm{Fe} /$ nano-AC would be weakened, which could be attributed that the amount of iron depositions directly decreased on the surface. Besides, when the F : Fe was below $3: 1$, the role of $\mathrm{F}$ could be decreased, and the amount of $\mathrm{Fe}^{3+}$ $\left(\mathrm{Fe}_{2} \mathrm{O}_{3}\right)$ would be reduced. Thus, the catalytic hydrolysis efficiency of $\mathrm{CS}_{2}$ over $\mathrm{Fe} /$ nano-AC would be also weakened when the $\mathrm{F}: \mathrm{Fe}$ was below $3: 1$. Table 3 showed the metal dispersion and $\mathrm{Fe}$ contents $\left(\mathrm{Fe}_{2} \mathrm{O}_{3}\right.$, wt\%) on the surface of $\mathrm{Fe} /$ nano-AC modified by different $\mathrm{F}:$ Fe. From Table 3, the metal dispersion increased from $2.73 \%$ to $8.01 \%$ when $\mathrm{F}$ : Fe was below $3: 1$. When $\mathrm{F}: \mathrm{Fe}$ was higher (above $3: 1$ ), the metal dispersion decreased from $8.01 \%$ to $5.10 \%$. Meanwhile, the results of $\mathrm{Fe}$ content are according with above analysis. It indicated that the content of $\mathrm{F}$ affected the formation of $\mathrm{Fe}^{3+}\left(\mathrm{Fe}_{2} \mathrm{O}_{3}\right)$ and then affected the dispersion of Fe.

To further research the influence of different $\mathrm{F}: \mathrm{Fe}$, the phase and crystalline orientations of $1: 1,3: 1,5: 1$ were

Table 3 Metal dispersion of Fe/nano-AC modified by different F : Fe ratio

\begin{tabular}{lll}
\hline Samples & Dispersion (\%) & Fe content $\left(\mathrm{Fe}_{2} \mathrm{O}_{3}, \mathrm{wt} \%\right)$ \\
\hline $\mathrm{F}: \mathrm{Fe}=1: 1$ & 2.73 & 12.6 \\
$\mathrm{~F}: \mathrm{Fe}=3: 1$ & 8.01 & 25.7 \\
$\mathrm{~F}: \mathrm{Fe}=5: 1$ & 5.10 & 21.3
\end{tabular}




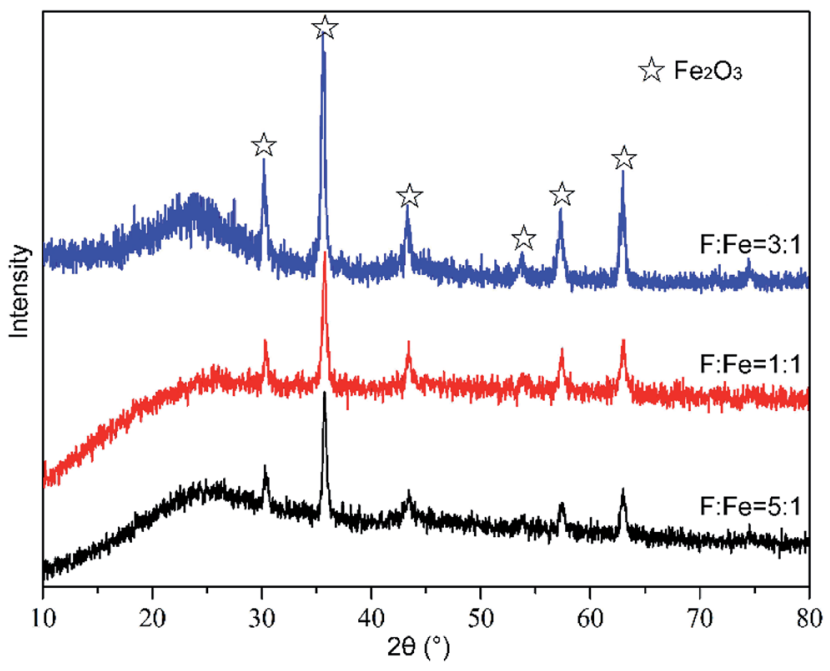

Fig. 5 XRD patterns of Fe/nano-AC modified by different $\mathrm{F}$ : Fe ratio.

investigated by XRD analysis and presented in Fig. 5 . It can be seen that peaks with strong intensity appear at $2 \theta=30.33^{\circ}$, $35.74^{\circ}, 43.41^{\circ}, 53.78^{\circ}, 57.39^{\circ}$ and $63.06^{\circ}$. These diffraction peaks are matched to $\mathrm{Fe}_{2} \mathrm{O}_{3}$, which exists on the surface nanocarbon and is treated as an active component. As shown in the Fig. 5 , the change of peak intensity of $\mathrm{Fe}_{2} \mathrm{O}_{3}$ could be used to investigate the influence of $\mathrm{F}: \mathrm{Fe}$. When $\mathrm{F}: \mathrm{Fe}$ rose from $1: 1$ to $3: 1$, the peak intensity of $\mathrm{Fe}_{2} \mathrm{O}_{3}$ increased with increasing $\mathrm{F}: \mathrm{Fe}$. It indicated that $\mathrm{FeCl}_{2}$ could turn into $\mathrm{Fe}_{2} \mathrm{O}_{3}$ with increasing of $\mathrm{F}: \mathrm{Fe}$, and $\mathrm{Fe}_{2} \mathrm{O}_{3}$ could enhance the hydrolytic activity. However, the peak intensity of $\mathrm{Fe}_{2} \mathrm{O}_{3}$ reduced rapidly when $\mathrm{F}: \mathrm{Fe}$ rose above $3: 1$. It indicated that high molar ratio of $\mathrm{F}: \mathrm{Fe}$ was not conducive to the generation of $\mathrm{Fe}_{2} \mathrm{O}_{3}$. Therefore, $\mathrm{F}: \mathrm{Fe}$ could lead to the change of active component on the surface of nano-AC. The XRD results can confirm the analysis of above paragraph.

\subsection{Influence of $\mathrm{pH}$ on catalytic hydrolysis of $\mathrm{CS}_{2}$}

Generally, the saturation degree of solution was closely relative to the solution $\mathrm{pH}$, which denotes $\mathrm{OH}^{-}$concentration and could obviously affect the formation of precursor of $\mathrm{Fe}^{3+}$ in the preparation processes of catalysts. ${ }^{31}$ Thus, the solution should be kept a suitable interval of supersaturation degree during the preparation process of catalysts. To further investigate the role of $\mathrm{pH}$ for catalytic activity, a series of $\mathrm{Fe} /$ nano-AC were prepared with different $\mathrm{pH}$. In this section, the content of $\mathrm{Fe}$ was $0.2 \mathrm{~mol} \mathrm{~L}^{-1} ; \mathrm{F}: \mathrm{Fe}$ was $3: 1$; calcination temperature was $500{ }^{\circ} \mathrm{C}$. The catalytic hydrolysis efficiency of $\mathrm{CS}_{2}$ over these catalysts are exhibited in Fig. 6 . The results showed that $\mathrm{CS}_{2}$ removal efficiency initially increased and then decreased with increasing $\mathrm{pH}$. The optimal $\mathrm{pH}$ is 5.1 and above $90 \% \mathrm{CS}_{2}$ conversion last $540 \mathrm{~min}$ at least.

Table 4 showed the metal dispersion and $\mathrm{Fe}$ content $\left(\mathrm{Fe}_{2} \mathrm{O}_{3}\right.$, wt $\left.\%\right)$ on the surface of $\mathrm{Fe} /$ nano-AC modified by different $\mathrm{pH}$. From Table 4 , the metal dispersion was $1.14 \%$ when $\mathrm{pH}$ was 4.7. When $\mathrm{pH}$ was 5.1 , the metal dispersion rose to $8.01 \%$. When $\mathrm{pH}$ was high (above 5.3), the metal dispersion decreased

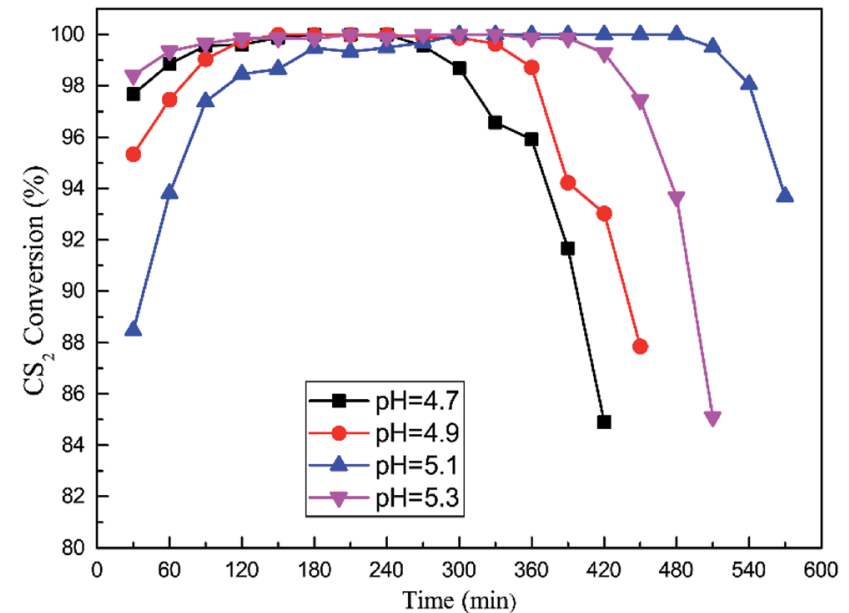

Fig. 6 Catalytic hydrolysis of $\mathrm{CS}_{2}$ over Fe/nano-AC modified by different $\mathrm{pH}$ (reaction conditions: $90 \mathrm{ppm} \mathrm{CS}$; GHSV $=10000 \mathrm{~h}^{-1}$; reaction temperature $=50^{\circ} \mathrm{C} ; \mathrm{RH}=11.8 \%$ ).

Table 4 Metal dispersion of Fe/nano-AC modified by different $\mathrm{pH}$

\begin{tabular}{lll}
\hline Samples & Dispersion $(\%)$ & Fe content $\left(\mathrm{Fe}_{2} \mathrm{O}_{3}, \mathrm{wt} \%\right)$ \\
\hline $\mathrm{pH}=4.7$ & 1.14 & 11.3 \\
$\mathrm{pH}=4.9$ & 4.71 & 20.8 \\
$\mathrm{pH}=5.1$ & 8.01 & 25.7 \\
$\mathrm{pH}=5.3$ & 6.80 & 23.1
\end{tabular}

from $8.01 \%$ to $6.80 \%$. For $\mathrm{pH}<5.1$, the precursor of $\mathrm{Fe}^{3+}\left(\mathrm{Fe}_{2} \mathrm{O}_{3}\right)$ did not reach the saturation degree in the solution, which led to less $\mathrm{Fe}_{2} \mathrm{O}_{3}$ deposits on the surface nano-carbon than that at $\mathrm{pH}=5.1$. When $\mathrm{pH}$ was above 5.1, the saturation degree was excessive high. A large number of the precursor of $\mathrm{Fe}^{3+}\left(\mathrm{Fe}_{2} \mathrm{O}_{3}\right)$ precipitation formed in the solution and no continuous film was gained on surface nano-carbon. It agreed with previous



Fig. 7 XRD patterns of Fe/nano-AC modified by different $\mathrm{pH}$. 
study. ${ }^{31}$ In addition, the result of XRD in Fig. 7 also showed that the peak intensity of $\mathrm{Fe}_{2} \mathrm{O}_{3}$ initially increased and then decreased with increasing solution $\mathrm{pH}$. It indicated that $\mathrm{pH}$ could lead to the change of the precursor of $\mathrm{Fe}^{3+}\left(\mathrm{Fe}_{2} \mathrm{O}_{3}\right)$ in the solution, which led to the change of $\mathrm{Fe}_{2} \mathrm{O}_{3}$ on the surface of catalyst. All of these factors which were discussed above would affect the activity of Fe/nano-AC on catalytic hydrolysis of $\mathrm{CS}_{2}$.

XPS analysis was performed to further clarify the influence of solution $\mathrm{pH}$ on catalytic hydrolysis of $\mathrm{CS}_{2}$. The Fe 2p XPS spectra of Fe/nano-AC modified by different $\mathrm{pH}$ (4.7, 4.9, 5.1 and 5.3) were showed in Fig. 8. Two obvious peaks of Fe 2p appeared at $710.75 \mathrm{eV}$ and $724.34 \mathrm{eV}^{32}$ In addition, two shake-up satellites with binding energies of $718.65 \mathrm{eV}$ and $733.31 \mathrm{eV}$ were also clearly observed. ${ }^{33}$ All of these features are typical of $\mathrm{Fe}_{2} \mathrm{O}_{3}$. By analysis the content of $\mathrm{Fe}^{2+}$ and $\mathrm{Fe}^{3+}$, the $\mathrm{Fe}^{3+} /\left(\mathrm{Fe}^{2+}+\mathrm{Fe}^{3+}\right)$ ratios decreased according to the sequence: $75.1 \%(\mathrm{pH}=5.1)>56.3 \%$ $(\mathrm{pH}=4.9)>54.7 \%(\mathrm{pH}=5.3)>48.0 \%(\mathrm{pH}=4.7)$. It indicated that $\mathrm{Fe}^{3+}$ was conductive to the removal of $\mathrm{CS}_{2}$. Fig. 8 also showed the peak separation of the $\mathrm{O} 1 \mathrm{~s}$ region for the different catalysts. The peaks of $\mathrm{O} 1 \mathrm{~s}$ were composed of three overlapping peaks: the chemical adsorbed oxygen (531.3-532.3 eV, marked


Fig. 8 XPS characterization results of Fe/nano-AC (Fe $2 p$ and $O 1 s$ ). as $\mathrm{O} \alpha$ ), the lattice oxygen (529.2-530.3 eV, marked as $\mathrm{O} \beta$ ) and the adsorbed water species presser on the surface (532.7$533.5 \mathrm{eV}$, marked as $\mathrm{O} \gamma) \cdot{ }^{34-36}$ As shown in Fig. 8, the ratio of $\mathrm{O} \alpha /$ $(\mathrm{O} \alpha+\mathrm{O} \beta+\mathrm{O} \gamma)$ over $\mathrm{Fe} /$ nano-AC at $\mathrm{pH}=5.1$ (32.6\%) was higher than $\mathrm{Fe} /$ nano-AC at $\mathrm{pH}=4.7(25.5 \%), \mathrm{Fe} /$ nano-AC at $\mathrm{pH}=4.9$ $(28.2 \%)$ and $\mathrm{Fe} /$ nano-AC at $\mathrm{pH}=5.3(25.9 \%)$. It indicated that low $\mathrm{O}$ content was conducive to the removal of $\mathrm{CS}_{2}$. According to above analysis, it can be found that $\mathrm{Fe}^{3+}$ and $\mathrm{O}$ groups was the main factors that affected the catalytic activity: $\mathrm{Fe}^{3+}$ affected the catalytic hydrolysis activity and $\mathrm{O}$ groups affected the oxidation activity.

\subsection{Influence of calcination temperatures on catalytic hydrolysis of $\mathrm{CS}_{2}$}

As an important process of catalyst preparation, the calcination temperature has a great influence on the activation, grain distribution, and formation of catalysts. The crystallinity and oxidation states can be changed at different calcination temperatures. Fig. 9 showed the influence of calcination temperatures on the catalytic hydrolysis of $\mathrm{CS}_{2}$ over the Fe/ nano-AC. In this section, the content of Fe was $0.2 \mathrm{~mol} \mathrm{~L}^{-1}$; $\mathrm{F}$ : Fe was $3: 1 ; \mathrm{pH}$ was 5.1. The results showed that the optimal calcination temperature is $500{ }^{\circ} \mathrm{C}$ for the catalytic hydrolysis of $\mathrm{CS}_{2}$. When the calcination temperature was above $600{ }^{\circ} \mathrm{C}$, the $\mathrm{CS}_{2}$ conversion efficiency reduced sharply. The surface oxidation of transition metals could be affected by the calcinations temperature. At low temperature (below $500{ }^{\circ} \mathrm{C}$ in this work), the final hydrolysis product $\left(\mathrm{H}_{2} \mathrm{~S}\right)$ might be oxidized into sulfate species and sulfur, which damaged hydrolysis active sites due to that the oxidizing nature of peroxy radicals may occur. ${ }^{37}$ In addition, it suggested that there is a certain relationship between the activity and the crystallinity of the oxidation state.

In order to further explain the influence of different calcination temperatures, the phase and crystalline orientations of $300{ }^{\circ} \mathrm{C}, 400{ }^{\circ} \mathrm{C}, 500{ }^{\circ} \mathrm{C}, 600{ }^{\circ} \mathrm{C}$ and $700{ }^{\circ} \mathrm{C}$ were investigated by $\mathrm{XRD}$ analysis and presented in Fig. 10. It can be seen that peaks

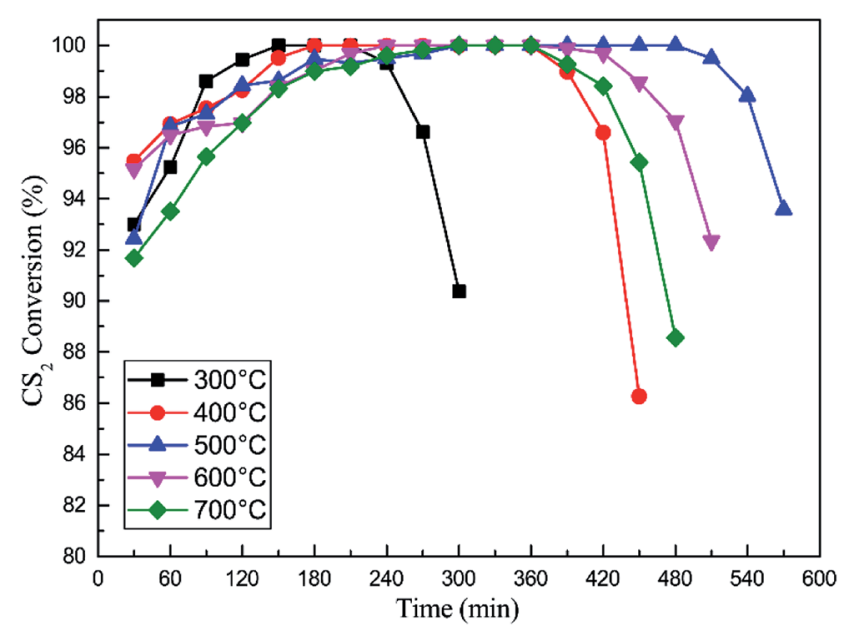

Fig. 9 Catalytic hydrolysis of $\mathrm{CS}_{2}$ over $\mathrm{Fe} /$ nano-AC modified by different calcination temperatures (reaction conditions: 90 ppm $\mathrm{CS}_{2}$; $\mathrm{GHSV}=10000 \mathrm{~h}^{-1}$; reaction temperature $=50{ }^{\circ} \mathrm{C} ; \mathrm{RH}=11.8 \%$ ). 




Fig. 10 XRD patterns of Fe/nano-AC modified by different calcination temperatures.
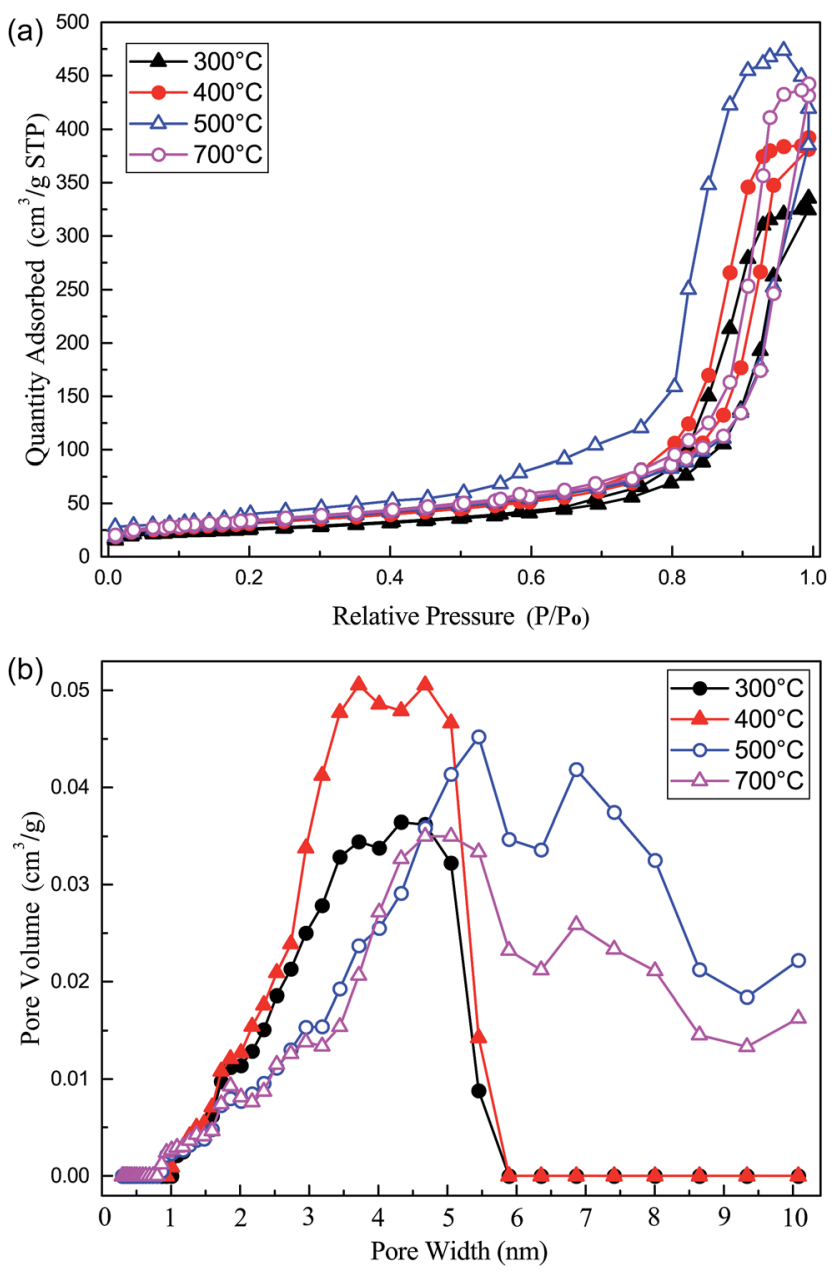

Fig. 11 (a) Nitrogen adsorption isotherms and (b) pore size distribution for Fe/nano-AC modified by different calcination temperatures.
Table 5 Porosity parameters of Fe/nano-AC modified by different calcination temperatures

\begin{tabular}{llll}
\hline Samples & $\begin{array}{l}\text { Surface area } \\
\left(\mathrm{m}^{2} \mathrm{~g}^{-1}\right)\end{array}$ & $\begin{array}{l}\text { Total pore volume } \\
\left(\mathrm{cm}^{3} \mathrm{~g}^{-1}\right)\end{array}$ & $\begin{array}{l}\text { Average pore } \\
\text { diameter }(\mathrm{nm})\end{array}$ \\
\hline $\mathrm{Fe} /$ nano-AC $\left(300^{\circ} \mathrm{C}\right)$ & 313 & 0.19 & 3.22 \\
$\mathrm{Fe} /$ nano-AC $\left(400^{\circ} \mathrm{C}\right)$ & 404 & 0.26 & 3.34 \\
$\mathrm{Fe} /$ nano-AC $\left(500^{\circ} \mathrm{C}\right)$ & 381 & 0.32 & 3.26 \\
$\mathrm{Fe} /$ nano-AC $\left(700^{\circ} \mathrm{C}\right)$ & 397 & 0.29 & 2.61
\end{tabular}

with strong intensity appear at $2 \theta=30.33^{\circ}, 35.74^{\circ}, 43.41^{\circ}$, $53.78^{\circ}, 57.39^{\circ}$ and $63.06^{\circ}$. The peak intensity of $\mathrm{Fe}_{2} \mathrm{O}_{3}$ increased with increasing calcination temperatures from $300{ }^{\circ} \mathrm{C}$ to $500{ }^{\circ} \mathrm{C}$. $\mathrm{Fe}_{2} \mathrm{O}_{3}$ can enhance the hydrolytic activity. However, the peak intensity of $\mathrm{Fe}_{2} \mathrm{O}_{3}$ reduced rapidly when the temperature rose steadily to above $600{ }^{\circ} \mathrm{C}$. It indicated that high calcination temperature was not conducive to the generation of $\mathrm{Fe}_{2} \mathrm{O}_{3}$. The reason is that dispersion of metal oxide particles on the surface of catalysts were damaged when the calcination temperature was excessive high, and the activity of catalyst could be decreased due to reunion and sintering. ${ }^{38}$ In addition, it would be occur that the pore structure of Fe/nano-AC was changed. We further confirmed this point according to the BET results.

Fig. 11a showed the nitrogen adsorption isotherms of some typical samples. The structural parameters were displayed in Table 5. According to the IUPAC classification, these samples exhibited an adsorption isotherms of type IV. It indicated that the samples were predominantly mesoporous materials. Meanwhile, the $\mathrm{N}_{2}$ adsorption capacity of $\mathrm{Fe} /$ nano-AC $\left(500{ }^{\circ} \mathrm{C}\right)$ was highest among the four catalysts. It can be concluded that the calcination temperature affected the surface area and pore volume. It showed similar distribution patterns for all the samples in Fig. 11b. It can be observed that the Fe/nano-AC $\left(500{ }^{\circ} \mathrm{C}\right)$ has more pores with a radius of $5-10 \mathrm{~nm}$ than that of others catalysts. This results suggest that more pore sizes of 5-10 $\mathrm{nm}$ play an important role in $\mathrm{CS}_{2}$ catalytic hydrolysis reactions. As mentioned above, the hydrolysis activity of the $\mathrm{Fe} /$ nano-AC was improved due to a large amount of pores $(5-10 \mathrm{~nm})$ at a calcination temperature of $500{ }^{\circ} \mathrm{C}$.

In our previous study, the reason for the deactivation of catalyst was the consumption of metal oxides (active compounds) and the generation of sulfate on the surface. ${ }^{4,39}$ The consumption of metal oxides led to the decrease of catalytic hydrolysis activity. The sulfate covered the adsorptive and catalytic active sites, which decreased the adsorptive and catalytic hydrolysis activities of catalyst. In these process, $\mathrm{H}_{2} \mathrm{~S}$ was oxidized into $\mathrm{S} / \mathrm{SO}_{4}{ }^{2-}$ and $\mathrm{Fe}_{2} \mathrm{O}_{3}$ was oxidized into $\mathrm{Fe}_{2}\left(\mathrm{SO}_{4}\right)_{3}$. In the future research, the mechanism of deactivation and catalyst regeneration will be further studied.

\section{Conclusions}

A series of nano-carbon based catalysts loaded metal oxides were prepared via liquid phase deposition, and used for low temperature catalytic hydrolysis of carbon disulfide $\left(\mathrm{CS}_{2}\right)$. The influences of preparation conditions for catalytic activity 
were investigated. These factors included species and content of metal oxides, ratio of $\mathrm{F}: \mathrm{Fe}$, solution $\mathrm{pH}$, and calcination temperature. Fe/nano-AC showed high efficiency on removal $\mathrm{CS}_{2}$. The results showed that $\mathrm{Fe} /$ nano-AC with $0.2 \mathrm{~mol} \mathrm{~L}{ }^{-1} \mathrm{Fe}$ ion after calcining at $500{ }^{\circ} \mathrm{C}$ had good catalytic activity for the catalytic hydrolysis of $\mathrm{CS}_{2}$. Furthermore, the catalytic hydrolysis activity could be up to the best with the optimum preparation conditions of ratio of $\mathrm{F}:$ Fe was $3: 1$, and solution $\mathrm{pH}$ was 5.1. Metal species affected the catalytic hydrolysis of $\mathrm{CS}_{2}$ and the oxidation of $\mathrm{H}_{2} \mathrm{~S}$. The solution $\mathrm{pH}$ and fluoride significantly affected the generation and formation of $\mathrm{Fe}^{3+}\left(\mathrm{Fe}_{2} \mathrm{O}_{3}\right)$. XRD results revealed that the formation of the crystalline phase of $\mathrm{Fe}_{2} \mathrm{O}_{3}$ was controlled by the calcination temperature. In addition, the BET results showed that the hydrolysis activity of the catalyst was affected by the amount of pores $(5-10 \mathrm{~nm})$. Future research will include the impact of potential poisonous pollutants in yellow phosphorus tail gas.

\section{Conflicts of interest}

There are no conflicts to declare.

\section{Acknowledgements}

This work was supported by the National Natural Science Foundation of China [51408282, 21667015]; China Scholarship Council [201508530017, 201608530169 and 201608740011] and the Analysis and Testing Foundation of Kunming University of Science and Technology.

\section{Notes and references}

1 T. J. Bandosz and Q. Le, Carbon, 1998, 36, 39-44.

2 A. Bagreev and T. J. Bandosz, Carbon, 2001, 39, 2303-2311.

3 K. Li, X. Song, P. Ning, H. Yi, X. Tang and C. Wang, Energy Technol., 2015, 3, 136-144.

4 X. Song, P. Ning, C. Wang, K. Li, L. Tang, X. Sun and H. Ruan, Chem. Eng. J., 2017, 314, 418-433.

5 A. Bagreev, F. Adib and T. J. Bandosz, Carbon, 2001, 39, 18971905.

6 K. Sakanishi, Z. H. Wu, A. Matsumura, I. Saito, T. Hanaoka, T. Minowa, M. Tada and T. Iwasaki, Catal. Today, 2005, 104, 94-100.

7 Z. Y. Xie, F. Wang, N. Zhao, W. Wei and Y. H. Sun, Appl. Surf. Sci., 2011, 257, 3596-3602.

8 H. H. Yi, K. Li, X. L. Tang, P. Ning, J. H. Peng, C. Wang and D. He, Chem. Eng. J., 2013, 230, 220-226.

9 C. C. Huang, C. H. Chen and S. M. Chu, J. Hazard. Mater., 2006, 136, 866-873.

10 Y. H. Xiao, S. D. Wang, D. Y. Wu and Q. Yuan, Sep. Purif. Technol., 2008, 59, 326-332.

11 A. Bagreev, J. A. Menendez, I. Dukhno, Y. Tarasenko and T. J. Bandosz, Carbon, 2004, 42, 469-476.

12 A. Sahibed-Dine, A. Aboulayt, M. Bensitel, A. B. M. Saad, M. Daturi and J. C. Lavalley, J. Mol. Catal. A: Chem., 2000, 162, 125-134.
13 Q. Li, H. Yi, X. Tang, S. Zhao, B. Zhao, D. Liu and F. Gao, Chem. Eng. J., 2016, 284, 103-111.

14 X. Sun, P. Ning, X. Tang, H. Yi, K. Li, D. He, X. Xu, B. Huang and R. Lai, J. Energy Chem., 2014, 23, 221-226.

15 H. Wang, H. Yi, P. Ning, X. Tang, L. Yu, D. He and S. Zhao, Chem. Eng. J., 2011, 166, 99-104.

16 Y. H. Yue, X. P. Zhao, W. M. Hua and Z. Gao, Appl. Catal., B, 2003, 46, 561-572.

17 P. D. Clark, N. I. Dowling and M. Huang, Appl. Catal., B, 2001, 31, 107-112.

18 H. H. Yi, D. He, X. L. Tang, H. Y. Wang, S. Z. Zhao and K. Li, Fuel, 2012, 97, 337-343.

19 P. Ning, K. Li, H. H. Yi, X. L. Tang, J. H. Peng, D. He, H. Y. Wang and S. Z. Zhao, J. Phys. Chem. C, 2012, 116, 17055-17062.

20 J. J. Schneider, Adv. Mater., 2001, 13, 529-533.

21 V. K. Gupta, N. Atar, M. L. Yola, Z. Ustundag and L. Uzun, Water Res., 2014, 48, 210-217.

22 Y. Li, X. Li, J. Chu, C. K. Dong, J. Y. Qi and Y. X. Yuan, Environ. Pollut., 2010, 158, 2317-2323.

23 H. Tian, J. J. Li, Q. Shen, H. L. Wang, Z. P. Hao, L. D. Zou and Q. Hu, J. Hazard. Mater., 2009, 171, 459-464.

24 J. M. Kim, S. M. Chang, S. Kim, K. S. Kim, J. Kim and W. S. Kim, Ceram. Int., 2009, 35, 1243-1247.

25 J. H. Wu, X. S. Li, Y. Zhao, W. P. Zhang, L. Guo and Y. Q. Feng, J. Chromatogr. A, 2011, 1218, 2944-2953.

26 T. Ohno, K. Numakura, H. Itoh, H. Suzuki and T. Matsuda, Adv. Powder Technol., 2011, 22, 390-395.

27 S. A. M. Samsuri, M. Y. A. Rahman, A. A. Umar and M. M. Salleh, J. Alloys Compd., 2015, 623, 460-465.

28 Q. Y. Li, R. N. Wang, Z. R. Nie, Z. H. Wang and Q. Wei, J. Colloid Interface Sci., 2008, 320, 254-258.

29 S. Deki, Y. Aoi, J. Okibe, H. Yanagimoto, A. Kajinami and M. Mizuhata, J. Mater. Chem., 1997, 7, 1769-1772.

30 C. Rhodes, S. A. Riddel, J. West, B. P. Williams and G. J. Hutchings, Catal. Today, 2000, 59, 443-464.

31 H. Pizem and C. N. Sukenik, Chem. Mater., 2002, 14, 24762485.

32 L. Lian, L. R. Hou, L. Zhou, L. S. Wang and C. Z. Yuan, RSC Adv., 2014, 4, 49212-49218.

33 Y. F. Liu, J. M. Xu, X. Y. Qin, H. X. Xin, X. Q. Yuan, J. Zhang, D. Li and C. J. Song, J. Mater. Chem. A, 2015, 3, 9682-9688.

34 J. C. Dupin, D. Gonbeau, P. Vinatier and A. Levasseur, Phys. Chem. Chem. Phys., 2000, 2, 1319-1324.

35 Y. Eom, S. H. Jeon, T. A. Ngo, J. Kim and T. G. Lee, Catal. Lett., 2008, 121, 219-225.

36 L. Chen, J. H. Li and M. F. Ge, Chem. Eng. J., 2011, 170, 531537.

37 L. Wang, D. Y. Wu, S. D. Wang and Q. Yuan, J. Environ. Sci., 2008, 20, 436-440.

38 Q. Zhang, I. Lee, J. B. Joo, F. Zaera and Y. Yin, Acc. Chem. Res., 2013, 46, 1816-1824.

39 H. H. Yi, H. Dan, X. L. Tang, H. Y. Wang, S. Z. Zhao and K. Li, Fuel, 2012, 97, 337-343. 